\title{
GOLD(I) WEAK BINDING SITES: HISTIDINE RESIDUES OF SERUM ALBUMIN
}

\author{
J. Xiao and C. Frank Shaw III \\ Department of Chemistry, University of Wisconsin-Milwaukee, Milwaukee, WI-53201-0413, USA
}

$\mathrm{Et}_{3} \mathrm{PAuCl}$, an analogue of the antiarthritic drug auranofin $\left[\mathrm{Et}_{3} \mathrm{PAuSATg}=\right.$ triethylphosphine- $(2,3,4,6-$ tetra-O-acetyl-1-thio-B-D-glucopyranosato-S)gold(I)] binds to weak binding sites of serum albumin in vitro. Up to 17 equivalents of $\mathrm{Et}_{3} \mathrm{PAu}^{+}$react with bovine serum albumin (BSA). These weak binding sites are characterized by ${ }^{31}$ P NMR shifts of $23-29 \mathrm{ppm}$ and may be the seventeen histidine residues.

In order to investigate these sites, a ${ }^{1} \mathrm{H}$ NMR study was performed. With a spin echo pulse sequence $(\tau=30 \mathrm{~ms})$, most of the $\mathrm{C} 2 \mathrm{H}$ resonances $(7.5-8.5 \mathrm{ppm})$ of the histidine imidazole rings of BSA were resolved. Their assignments as the $\mathrm{C} 2 \mathrm{H}$ of the histidines were confirmed by a ${ }^{1} \mathrm{H}$ NMR $\mathrm{pH}$ titration. Upon titrating $\mathrm{BSA}$ with $\mathrm{Et}_{3} \mathrm{PAuCl}$, shifting and broadening of these $\mathrm{C} 2 \mathrm{H}$ resonances occurred. $\mathrm{Et}_{3} \mathrm{PAu}^{+}$bound preferentially to the more hydrophobic histidine residues characterized by shorter $\mathrm{T}_{2}$ relaxation times. All the resonances were eventually undetectable. The same phenomena (broadening and shifting of the $\mathrm{C} 2 \mathrm{H}$ resonance) were observed in model studies in which L-histidine and $\mathrm{N}$-acetyl-L-histidine were titrated with $\mathrm{Et}_{3} \mathrm{PAuCl}$. 